\title{
PROTÓTIPO DE TRANSMISSÃO DE DADOS A BAIXO CUSTO PARA O MONITORAMENTO DE POÇOS TUBULARES POR TELEMETRIA (WIFI)
}

\author{
Marcus Vinicios Andrade Silva ${ }^{1}$; Leonardo Augusto Resende Goulart²; Michelle Cintra Abud \\ Mariano $^{3}$; Vitor Magalhães Maciel ${ }^{4}$; Luiz Gustavo Moraes de Macedo ${ }^{5}$ \& Ramon Vinhas Oliveira \\ $\operatorname{Lima}^{6 .}$
}

\section{Resumo}

O monitoramento dos poços tubulares é de extrema importância, não só por questões ambientais e legais, mas também para garantir o melhor desempenho do poço e a longevidade do mesmo. Este artigo é baseado em um trabalho de conclusão de curso (TCC) da Engenharia de Automação Industrial do CEFET MG (Campus Araxá). O TCC foi motivado pela necessidade de monitorar os poços de rebaixamento de uma das minas da Vale Fertilizantes por meio de um sistema de baixo custo de implantação e fácil operação. Além das questões legais da outorga, falhas de monitoramento podem gerar períodos de paradas do sistema de bombeamento, acarretando um aumento do nível de água subterrânea, criando transtornos operacionais às atividades de lavra. $\mathrm{O}$ monitoramento das vazões e do próprio funcionamento dos poços é feita de forma convencional (leituras manuais) e diária, acarretando transtornos como: demanda de tempo dos funcionários, necessidade de veículos, erros durante coleta dos dados, dificuldade/falta de acesso ao poço, entre outros. O objetivo principal foi propor um sistema de monitoramento remoto de baixo custo, e este artigo apresenta um protótipo em torno de $\mathrm{R} \$ 1000$ (mil reais) por poço com aplicabilidade inclusive em áreas urbanas.

\footnotetext{
${ }^{1}$ Vale Fertilizantes: Av. Arafértil, 5000 - CEP: 38184-270 - Araxá-MG; (34)3669-6231 fax: (34) 3669-6300; marcus.andrade@ valefert.com.

${ }^{2}$ CEFET MG, Av. Min. Olavo Drummond, No 25 - 38180-510 - Araxá \MG, fone: 34 3669-4500, fax: 34 3669-4500, leo_gral8@hotmail.com.

${ }^{3}$ Vale Fertilizantes: Av. Arafértil, 5000 - CEP: 38184-270 - Araxá-MG; (34)3669-6317; fax: (34) 3669-6300; michelle.abud@ valefert.com.

${ }^{4}$ Vale Fertilizantes: Av. Arafértil, 5000 - CEP: 38184-270 - Araxá-MG; (34)3669-6388; fax: (34) 3669-6300; vitor.maciel@ valefert.com

${ }^{5}$ Vale Fertilizantes: Rodovia MG 341, Km 25 - CEP: 38185-000 - Tapira-MG; (34)3669-5411; fax: (34) 3669-6300; luiz.macedo@ valefert.com.

${ }^{6}$ Instituto Passo 1: Av. Fernando Vilela, 2030 - CEP: 38400-456 - Uberlândia-MG, (34)3221-4300; ramon.vinhas@ gmail.com.
} 


\begin{abstract}
The monitoring of wells is extremely important, not only for environmental and legal issues, but also to ensure better well performance and longevity of it. This article is based on a completion of course work (TCC) of the Industrial Automation Engineering CEFET MG (Campus Araxá). The TCC was motivated by the need to monitor the drawdown wells of a mine of Vale Fertilizantes through a low-cost deployment and easy operation system. In addition to the legal issues of the grant, fault monitoring can generate periods of the pumping system stops, resulting in an increase in the groundwater level, creating operational disruptions to mining activities. The monitoring of flow rates and the proper operation of the wells is done conventionally (manual readings) and daily, resulting in disorders such as staff time demand, the need for vehicles errors during data collection, difficulty / lack of access to the well, among others. The main objective was to propose a remote monitoring of low-cost system, and this article presents a prototype around R \$1,000 (one thousand reais) per well with applicability even in urban areas.
\end{abstract}

Palavras-Chave - Telemetria. Poços Tubulares. Monitoramento. 


\section{1 - INTRODUÇÃO}

O uso das águas subterrâneas vêm crescendo cada vez mais, principalmente em função das alterações climáticas e constantes crises no abastecimento público, o que leva a sociedade e procurar alternativas rápidas e com o menores custos, ocasionando a perfuração de poços, muitas vezes de forma clandestina, seja por questões de lentidão dos órgãos reguladores em processos de licenciamentos e outorgas, ou mesmo devido ao custo para manter um responsável técnico e os devidos monitoramentos exigidos por lei.

O trabalho de conclusão de curso da Engenharia de Controle e Automação do CEFET MG (Campus Araxá) intitulado "Monitoramento Remoto de Poços Tubulares na Mineração" apresenta uma solução interessante e de baixo custo para o monitoramento de poços tubulares e pode ser adaptado em qualquer ramo de atividade. O TCC em questão foi baseado na exploração de uma mina em cava fechada, a qual necessita de rebaixamento de nível de água (n.a), uma vez que essa nem sempre apresenta condições favoráveis de drenagem superficial. Segundo Bertachini e Almeida (2003) essa é uma prática comum iniciada na década de 1980) para a viabilização operacional das minas que atingiram os níveis de águas subterrâneas ao longo das escavações. Atualmente as mineradoras fazem uso de poços tubulares profundos para realizar esta função de rebaixamento de n.a e assim permitir o avanço da lavra e a operabilidade da mina (ABUD et al., 2014).

Para que se possa obter a outorga dos poços de rebaixamento e consequentemente viabilizar a extração é necessário que se cumpra uma série de critérios legais antes e depois da instalação dos mesmos. O que interessa aqui é o critério de operação dos poços já instalados: o monitoramento dos volumes de água retirados da mina. Para o devido cumprimento da legislação vigente, a empresa possui funcionários responsáveis pelo monitoramento e funcionamento dos poços. Essas atividades realizadas diária e manualmente ocasionam alguns transtornos como:

a) demanda de tempo do operador, ter que ir a todos os poços;

b) erros durante a coleta dos dados, esquecimento da leitura de algum poço e/ou troca de dados;

c) dificuldade ou mesmo falta de acesso, o processo de lavra e as condições climáticas às vezes cortam, temporariamente, o acesso ao poço (dessa forma não se consegue obter a leitura nem mesmo saber o funcionamento do poço em questão);

d) não possuir o levantamento dos poços em operação em tempo real e

e) segurança, uma vez que a operação de lavra acarreta riscos para aqueles que ali estão trabalhando. 
Por meio da telemetria e de um sistema de supervisório propôs-se uma otimização do processo acima citado obtendo um acesso remoto instantâneo e confiável às informações de cada poço, tais como:

1) funcionamento (ligado/desligado/falha de sobrecarga/falha de comunicação), caso o radiotransmissor pare de funcionar por quaisquer motivos;

2) vazão instantânea;

3) totalizador da vazão;

No mercado, existem empresas que produzem sistemas de telemetria que atendem essa aplicação de monitoramento de poços. Diferentes técnicas de transmissão de dados são utilizadas e, geralmente, têm um elevado custo de instalação, bem como taxas mensais de manutenção dos sistemas instalados.

\section{2 - OBJETIVOS}

\section{1 - Objetivo geral}

O projeto dedica-se em otimizar, de forma remota, o processo de controle e coleta de dados dos poços tubulares profundos de uma mineradora, dando confiabilidade e um controle simultâneo ao processo de rebaixamento de n.a subterrânea, visando um baixo custo de implantação e manutenção. No projeto, serão utilizados três dispositivos radiotransmissores de padrão ZigBee, formando uma rede. Um deles será acessado de uma estação remota (notebook) e assim receberá os dados triviais de funcionamento dos dois poços monitorados.

\section{2 - Objetivos específicos}

a) Estudo da tecnologia wireless padrão ZigBee;

b) Configuração e testes de comunicação entre módulos XBee-PRO ZigBee;

c) Programação de um microcontrolador Atmel para tratamentos dos dados de funcionamento do poço juntamente com o módulo ZigBee;

d) E desenvolvimento de um supervisório utilizando o software Microsoft Visual Studio.

\section{3 - MATERIAIS E MÉTODOS}

O desenvolvimento da pesquisa é baseado no protótipo apresentado na Figura 1. O projeto utilizou três dispositivos radiotransmissores de padrão DigiMesh formando uma rede, onde um deles 
será acessado de uma estação remota (notebook) que receberá os dados de funcionamento dos poços monitorados (PP-01 e PP-02).

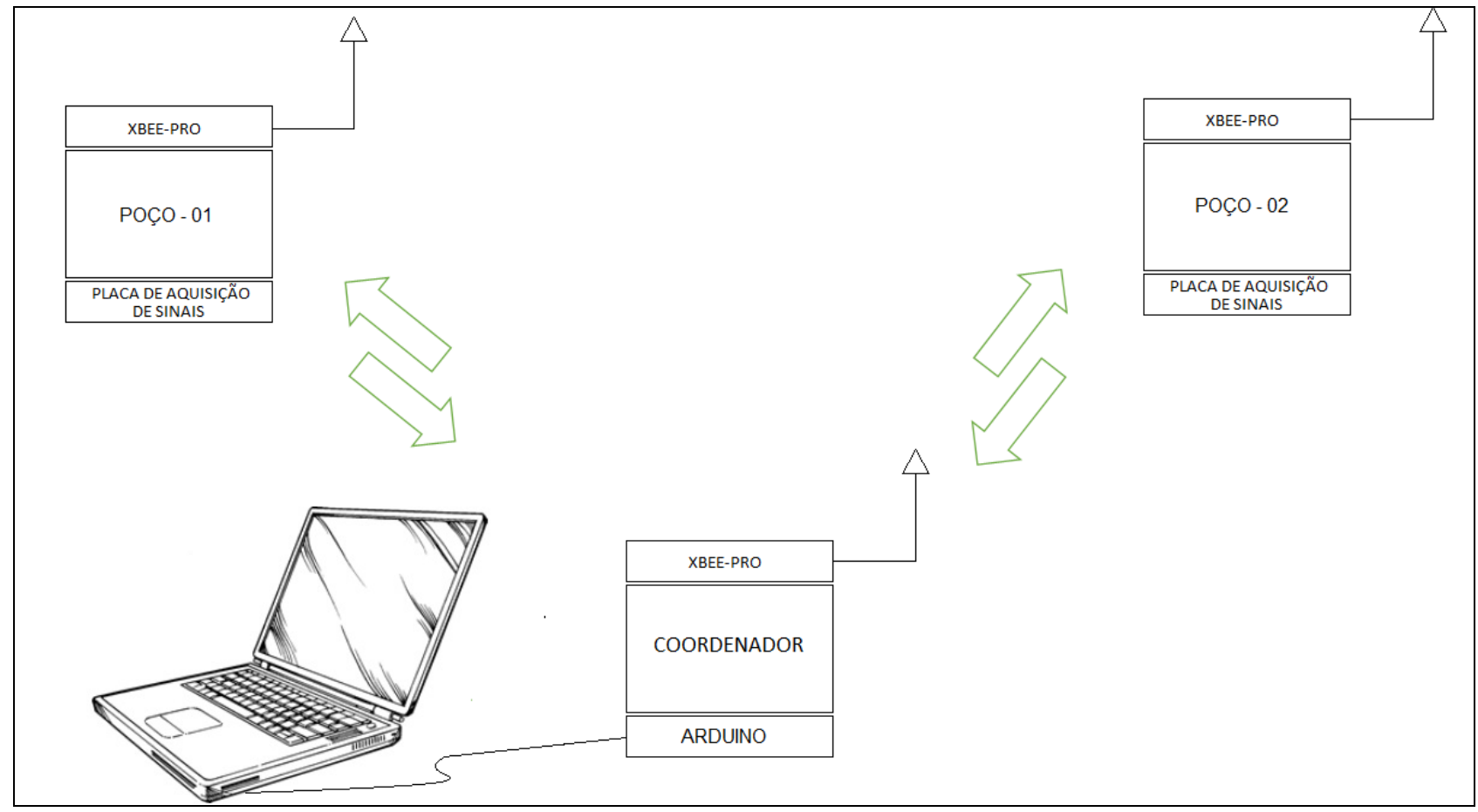

Figura 1: Protótipo do projeto de monitoração de poços tubulares (Fonte: Goulart, 2015).

Para facilitar o desenvolvimento do projeto proposto, ele foi dividido em:

a) Sistema de rádio transmissão: apresenta-se o radiotransmissor utilizado e os acessórios necessários para configuração e funcionamento correto dos módulos. Mostra como foi feita a configuração dos módulos e os primeiros testes de comunicação entre os dispositivos;

b) Sistema de interface e aquisição de dados dos rádios: apresenta-se a interface necessária para receber um dado;

c) Sistema de supervisão e tratamento de dados: criação do aplicativo e representação dos sinais recebidos dos XBee;

d) Sistema de aquisição de sinais de campo: placa de simulação dos sinais monitorados;

e) E teste de alcance: a distância em que há transmissão sem perda de dados.

O custos unitários para a montagem do protótipo são detalhados na tabela 1, totalizando um valor de $\mathrm{R} \$ 3019,21$ para a aquisição de equipamentos suficientes para monitorar 3 poços, ou seja, um custo de aproximadamente $\mathrm{R} \$ 1006,40$ por poço. 
Tabela 1: Custos em $\mathrm{R} \$$ das peças e equipamentos do protótipo

\begin{tabular}{|c|c|c|c|c|c|c|}
\hline \multirow{2}{*}{$\frac{\text { QTD }}{4}$} & \multirow{2}{*}{$\frac{\text { UNID }}{\text { METROS }}$} & \multirow[b]{2}{*}{ CABO RGC HFE } & \multicolumn{2}{|c|}{ CUSTO UNIT. } & \multicolumn{2}{|c|}{ CUSTO } \\
\hline & & & $\mathrm{R} \$$ & 2.42 & $\mathrm{R} \$$ & 9.68 \\
\hline 8 & PEÇAS & CONECTOR N MACHO SOLDA & $\mathrm{RS}$ & 14.55 & 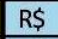 & 87.31 \\
\hline 2 & PEÇAS & CONECTOR PIGTAIL SMA & $\mathrm{R} \$$ & 23.75 & $\mathrm{R} \$$ & 47.50 \\
\hline 1 & PEÇAS & XBEE SHIELD & $\mathrm{R} \$$ & 44.90 & $\mathrm{R} \$$ & 44.90 \\
\hline 1 & PEÇAS & ARDUINO UNO & $\mathrm{R} \$$ & 59.90 & $\mathrm{R} \$$ & 59.90 \\
\hline 1 & PEÇAS & BARRA DE 40 PINOS HEADER X5 UNIDADES & $\mathrm{R} \$$ & 9.90 & $\mathrm{R} \$$ & 9.90 \\
\hline 1 & PEÇAS & FERRO DE SOLDA & $\mathrm{RS}$ & 44.90 & $\mathrm{R} \$$ & 44.90 \\
\hline 1 & PEÇAS & MULTIMETRO DIGITAL MINIPA ET-1005 & $\mathrm{R} \$$ & 39.90 & $\mathrm{R} \$$ & 39.90 \\
\hline 1 & PEÇAS & JUMPERS FEMEA-FEMEA X40 UNIDADES & $\mathrm{R} \$$ & 19.90 & $\mathrm{R} \$$ & 19.90 \\
\hline 1 & PEÇAS & KIT JUMPERS MACHO-MACHO X65 UNIDADES & $\mathrm{R} \$$ & 19.90 & $\mathrm{R} \$$ & 19.90 \\
\hline 1 & PEÇAS & KIT JUMPERS MACHO-FEMEA X40 UNIDADES & $\mathrm{R} \$$ & 19.90 & $\mathrm{R} \$$ & 19.90 \\
\hline 1 & FRETE & FRETE FELIPE FLOP & $\mathrm{R} \$$ & 17.01 & $\mathrm{R} \$$ & 17.01 \\
\hline 2 & PEÇAS & Módulo Digi Xbee-PRO DigiMesh 900HP - Conector UFL - Extended-Range & $\mathrm{R} \$$ & 259.28 & $\mathrm{R} \$$ & 518.56 \\
\hline 1 & FRETE & FRETE XBEE STORE & $\mathrm{R} \$$ & 36.34 & $\mathrm{RS}$ & 36.34 \\
\hline 2 & PEÇAS & Módulo Digi Xbee-PRO DigiMesh 900HP - Conector Wire - Extended-Range & $\mathrm{R} \$$ & 296.32 & $\mathrm{RS}$ & 592.64 \\
\hline 1 & FRETE & FRETE XBEE STORE & $\mathrm{R} \$$ & 39.53 & $\mathrm{R} \$$ & 39.53 \\
\hline 3 & PEÇAS & ANTENA OMNIDIRECIONAL 9dBi & $\mathrm{R} \$$ & 285.00 & $\mathrm{RS}$ & 855.00 \\
\hline 1 & PEÇAS & XBEE SHIELD & $\mathrm{R} \$$ & 39.90 & $\mathrm{R} \$$ & 39.90 \\
\hline 1 & FRETE & FRETE FELIPE FLOP & $\mathrm{R} \$$ & 15.88 & 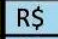 & 15.88 \\
\hline 1 & PEÇAS & Kit Iniciante V7 para Ardu ino com Arduino UNO R3 & $\mathrm{R} \$$ & 179.00 & $\mathrm{R} \$$ & 179.00 \\
\hline 1 & FRETE & FRETE ROBOCORE & $\mathrm{R} \$$ & 38.92 & $\mathrm{R} \$$ & 38.92 \\
\hline 2 & PEÇAS & Conector empilhável - 6 pinos & $\mathrm{RS}$ & 1.75 & $\mathrm{RS}$ & 3.50 \\
\hline 2 & PEÇAS & Conector empilhável - 8 pinos & $\mathrm{R} \$$ & 1.75 & $\mathrm{R} \$$ & 3.50 \\
\hline 2 & PEÇAS & Xbee Explorer Dongle & $\mathrm{R} \$$ & 119.00 & $\mathrm{R} \$$ & 238.00 \\
\hline 1 & FRETE & FRETE ROBOCORE & $\mathrm{R} \$$ & 37.74 & $\mathrm{RS}$ & 37.74 \\
\hline
\end{tabular}

\section{4 - RESULTADOS}

Serão abordados neste item os resultados individuais de cada sistema citado anteriormente, e posteriormente uma análise dos mesmos.

\section{1 - Sistema de rádio transmissão}

A configuração dos módulos em modo transparente foi realizada. Uma vez criada a rede entre os módulos, todos dados escritos no terminal (onde se envia e recebe dados da porta serial) do software XCTU em um dos notebooks devem aparecer na outra tela do terminal do software XCTU do outro notebook, confirmando que a rede entre os módulos foi estabelecida.

Na Figura 2, nota-se que XBee à esquerda transmite o sinal: a palavra LEONARDO, em azul, mostrando que está enviando. Já o outro XBee recebe a palavra LEONARDO, em vermelho, sinal que está recebendo (Figura 2). De forma análoga, o Xbee da esquerda transmite a mesma palavra (azul) e o XBee da direita recebe a palavra LEONARDO, confirmando a comunicação entre os módulos. 


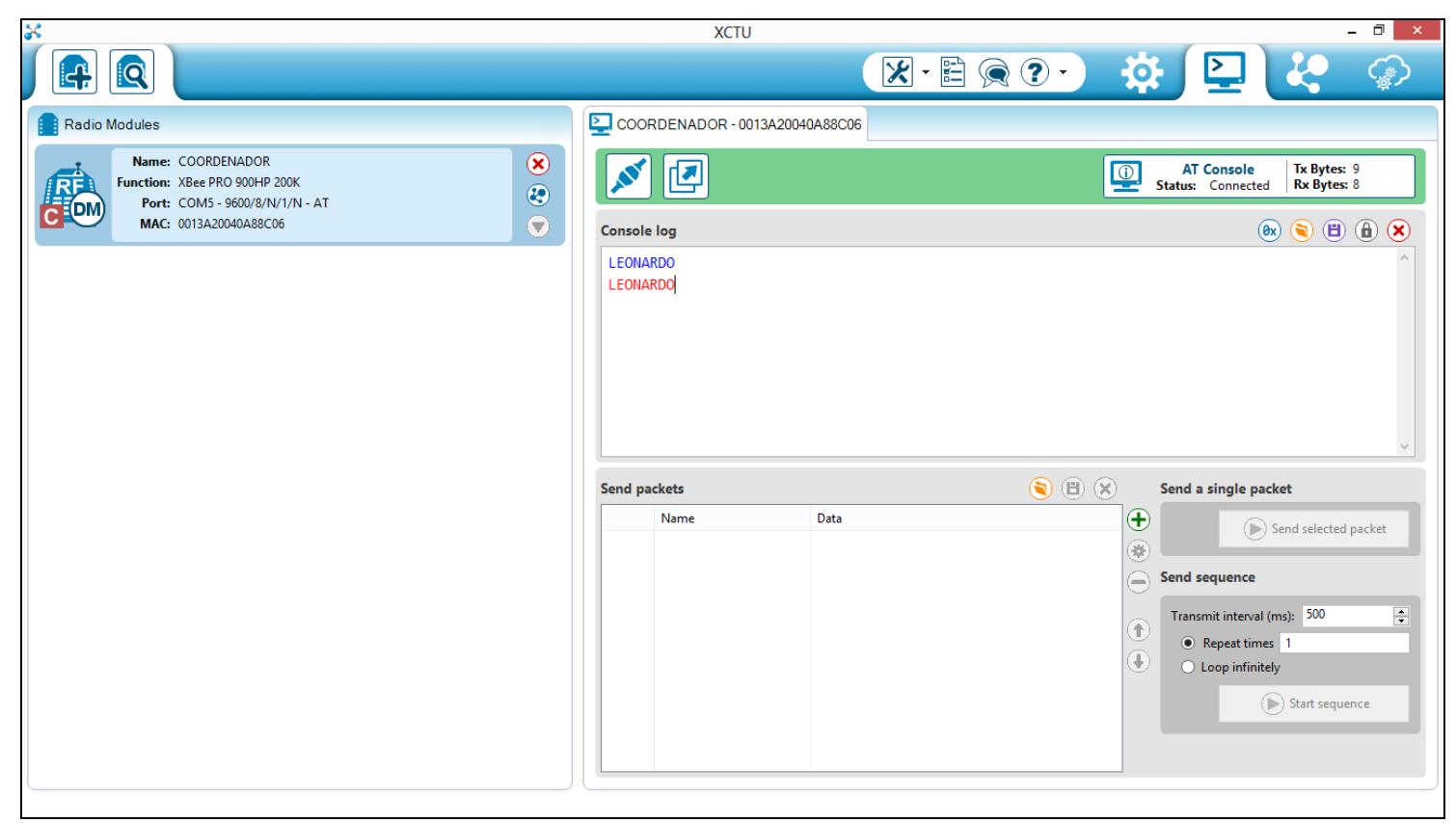

Figura 2: Transmissão e recepção em modo transparente, notebook à direita (Fonte: Goulart, 2015).

Os módulos XBee configurados nesse modo transparente transmitem e recebem os sinais em sua porta serial, mas podem fazer o mesmo em suas portas de entradas e saídas digitais e analógicas, caso elas estejam configuradas. Porém, essa forma de comunicação não atende à aplicação proposta, a de monitorar dois poços. Por isso a necessidade de configurá-los em modo API. Dessa forma, os dois módulos que estavam em modo transparente (AT) foram configurados para modo API. Foi adicionado um novo dispositivo que recebeu o mesmo endereço de rede dos outros dois.

Para verificar o funcionamento da rede em novo modo, após a configuração individual de cada Xbee, o XBee coordenador (nome dado ao primeiro Xbee que criou a rede, e será responsável por receber os dados advindos dos outros $\mathrm{XBee}$ ) foi novamente conectado ao XCTU e os outros dois foram energizados. O software XCTU possui uma função chamada discovery radio devices (descobrir dispositivos rádios). Caso venha a ser usada, ela encontra todos os rádios que estão na mesma rede. Função utilizada para confirmar a nova rede agora com três dispositivos (Figura 3).

Esse modo de comunicação API é mais vantajoso. Uma vez que é possível configurar os outros módulos remotamente, não necessitando programar individualmente cada módulo (Figura 4).

Neste modo, foram definidos o nome e a função de cada dispositivo, conforme a Figura 5.

a) PP-01: enviar periodicamente os sinais de suas entradas digitais e de sua porta analógica ANO;

b) PP-02: possui a mesma função do PP-01;

c) Coordenador: tem a função de receber os dados enviados do PP-01 e PP-02. 


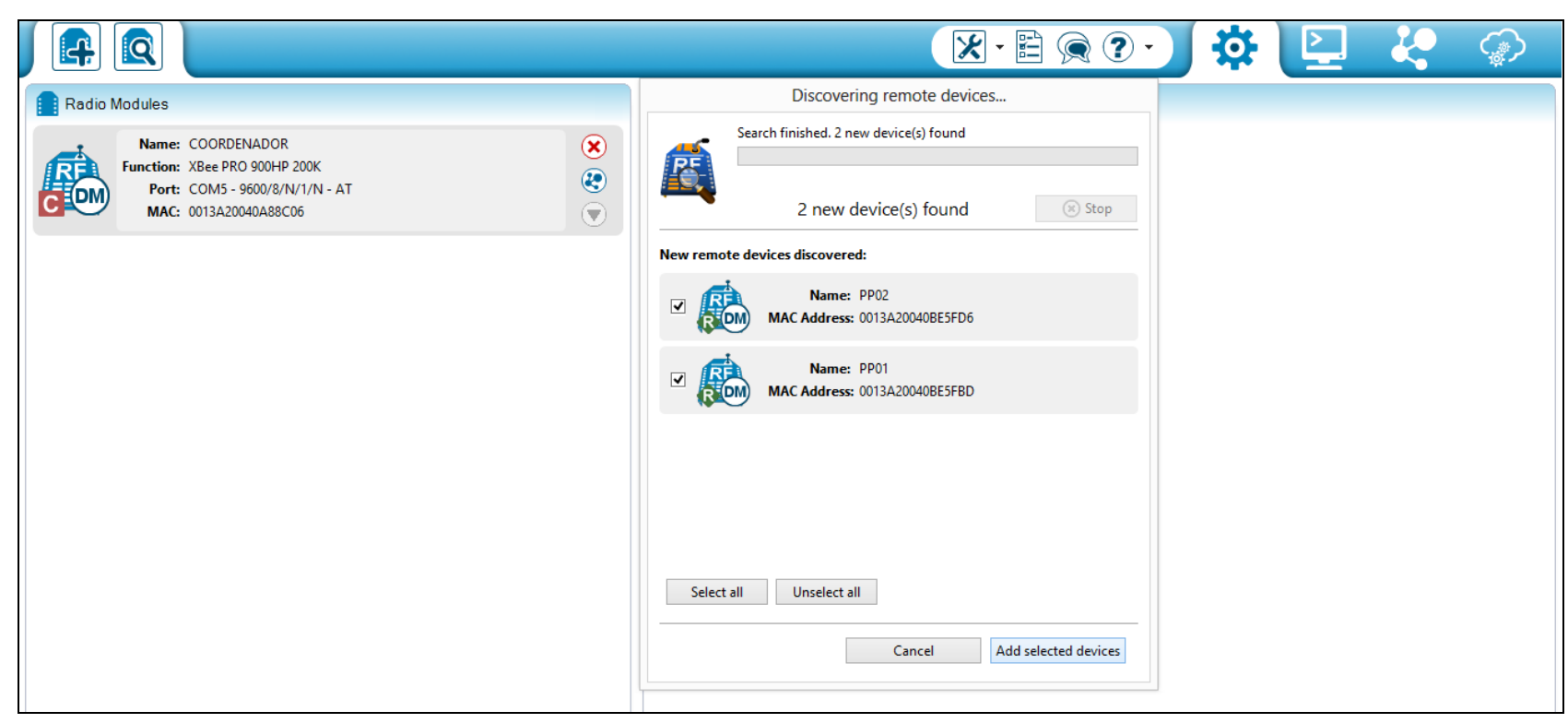

Figura 3: Função discovery radio devices (Fonte: Goulart, 2015).

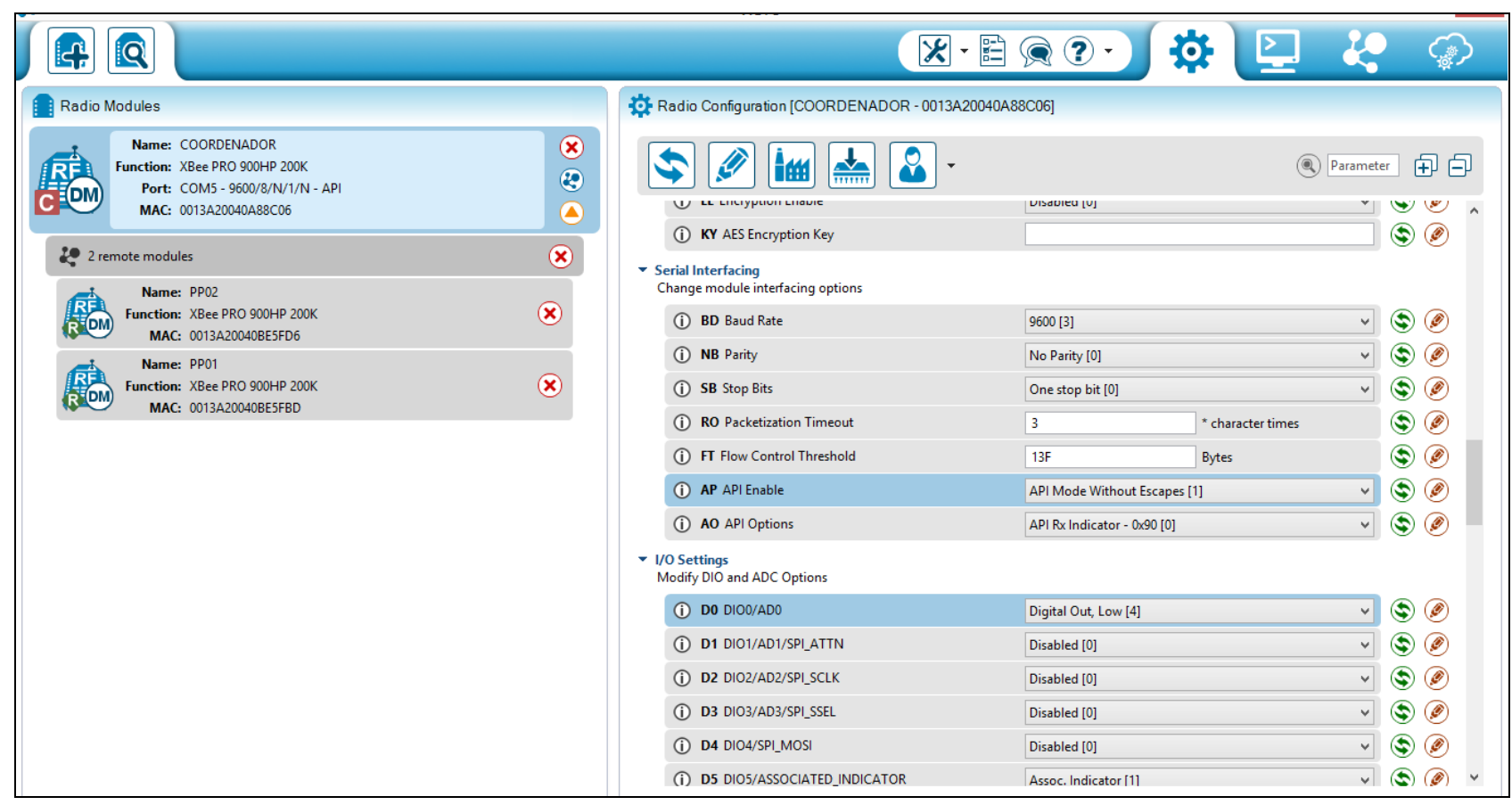

Figura 4: Configuração remota dos módulos (Fonte: Goulart, 2015).

\section{2 - Sistema de interface e aquisição de dados dos rádios}

Nesse sistema o Arduino é programado para receber os dados advindos do PP-01 e PP-02 e então retransmiti-los em sua porta serial. O IDE do Arduino possui um monitor serial 66 onde podemos monitorar o que é enviado pela porta serial do Arduino. Assim, após fazer a programação Arduino e conectar o sistema de aquisição de dados, foi aberto o monitor serial e verificado os frames enviados do PP-01 e do PP-02 (Figura 5). 


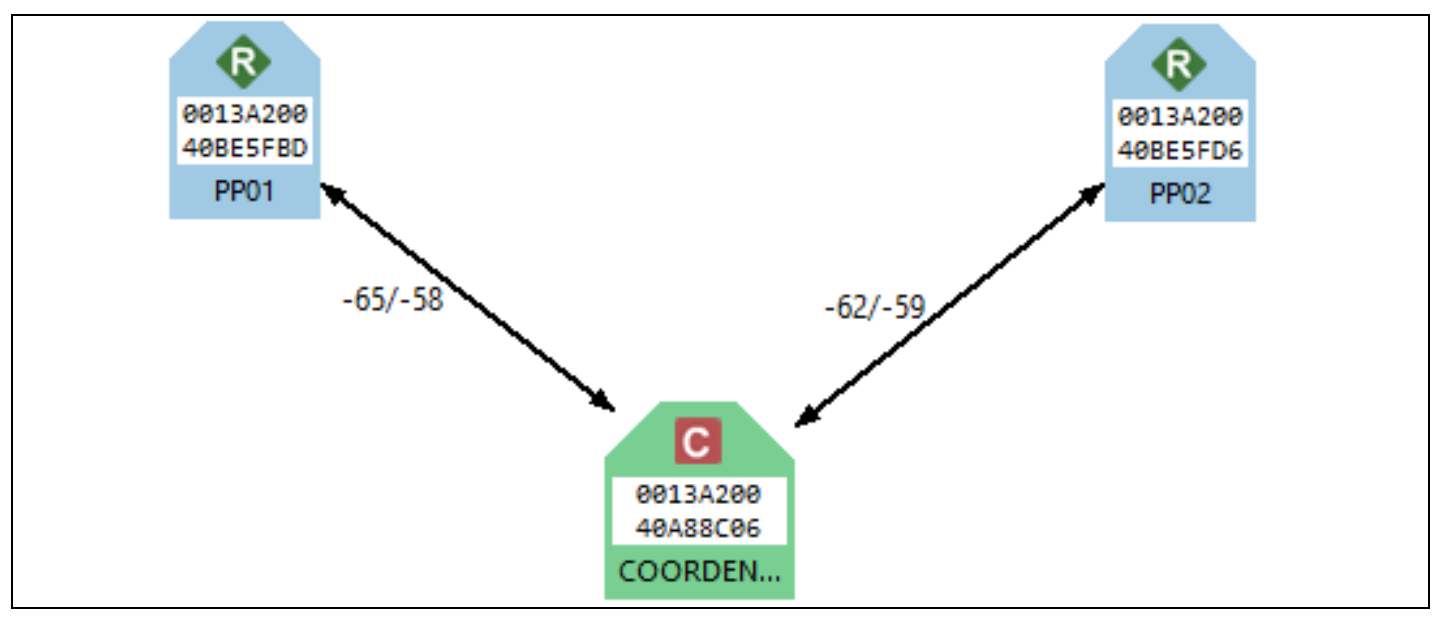

Figura 5: Nome e função dos dispositivos em modo API (Fonte: Goulart, 2015).

\section{3 - Sistema de supervisão e tratamento de dados}

O sistema de supervisão, aplicativo desenvolvido no software Microsoft Visual Studio, trata os dados frame (ZigBee IO Data Sample) que são recebidos pela porta serial 67 do sistema de interface e aquisição, de forma que esses dados se tornem números, animações e alarmes na tela de supervisão. Para iniciar o sistema, o aplicativo possui um local para escolha da porta serial que o Arduino está conectado (Figura 6).

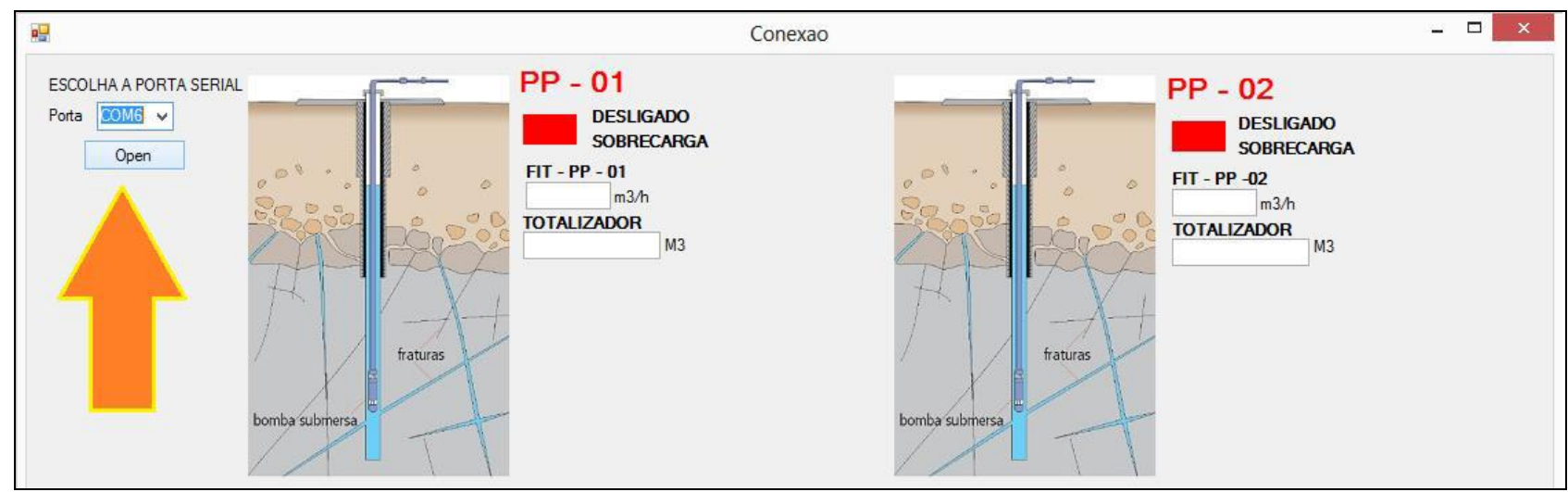

Figura 6: Escolha da porta serial do aplicativo de supervisão (Fonte: Goulart, 2015).

O aplicativo é capaz de monitorar nos dois dispositivos XBee (Figura 7):

a) status da bomba: ligado (VERDE), desligado (AZUL) e falha (sobrecarga, VERMELHO);

b) falha de comunicação: caso o dispositivo venha a falhar o envio de dados (status BRANCO e um alarme - FALHA DE COMUNICAÇÃO PP-0X);

c) vazão instantânea: conversão do sinal analógico (ANO - pino XBee) ou cálculo do sinal pulsante (DI10); 
d) totalizador: acumulado das vazões instantâneas.

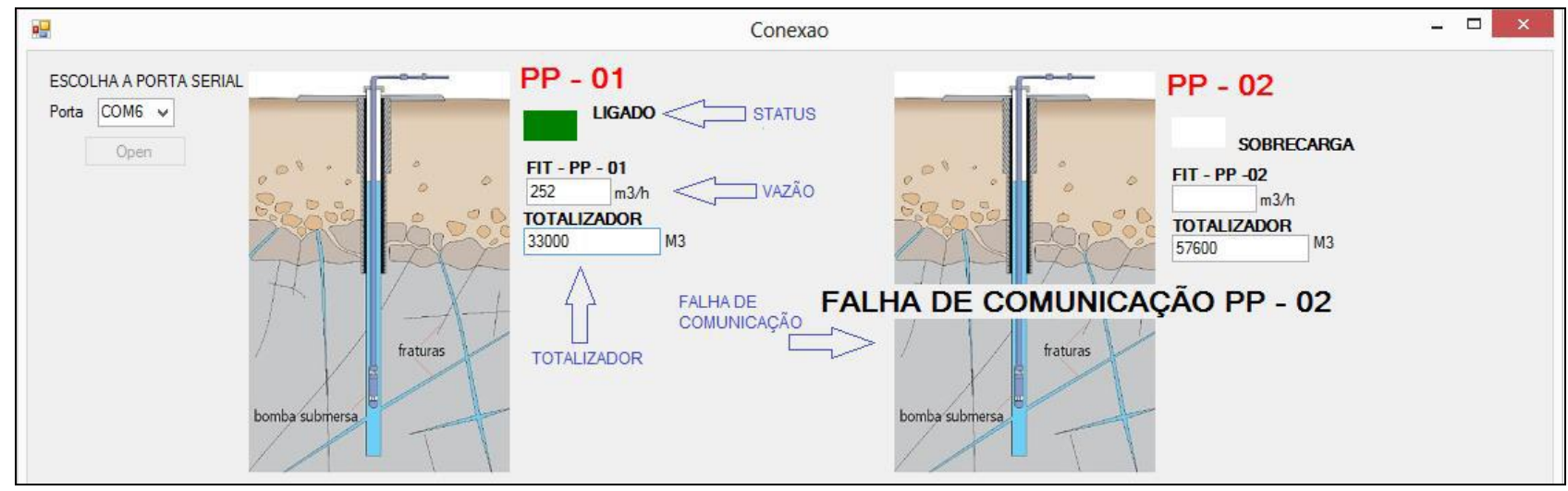

Figura 7: Sinais monitorados pelo aplicativo (Fonte: Goulart, 2015).

\section{4 - Sistema de aquisição de sinais de campo}

A Figura 8 mostra o sistema de aquisição dos sinais de campo montado. Esse sistema simula os sinais definidos para monitorar um poço. O protótipo foi necessário para o desenvolvimento do trabalho. Os sinais discretos são simulados por jumpers conectados ao terra. Já o sensor LM35 é um sensor de temperatura (que possui em sua saída um sinal de 10 milivolts $(\mathrm{mV})$ para cada grau Celsius de temperatura). O sinal analógico do sensor LM35 simula o sinal que viria do sensor de vazão.

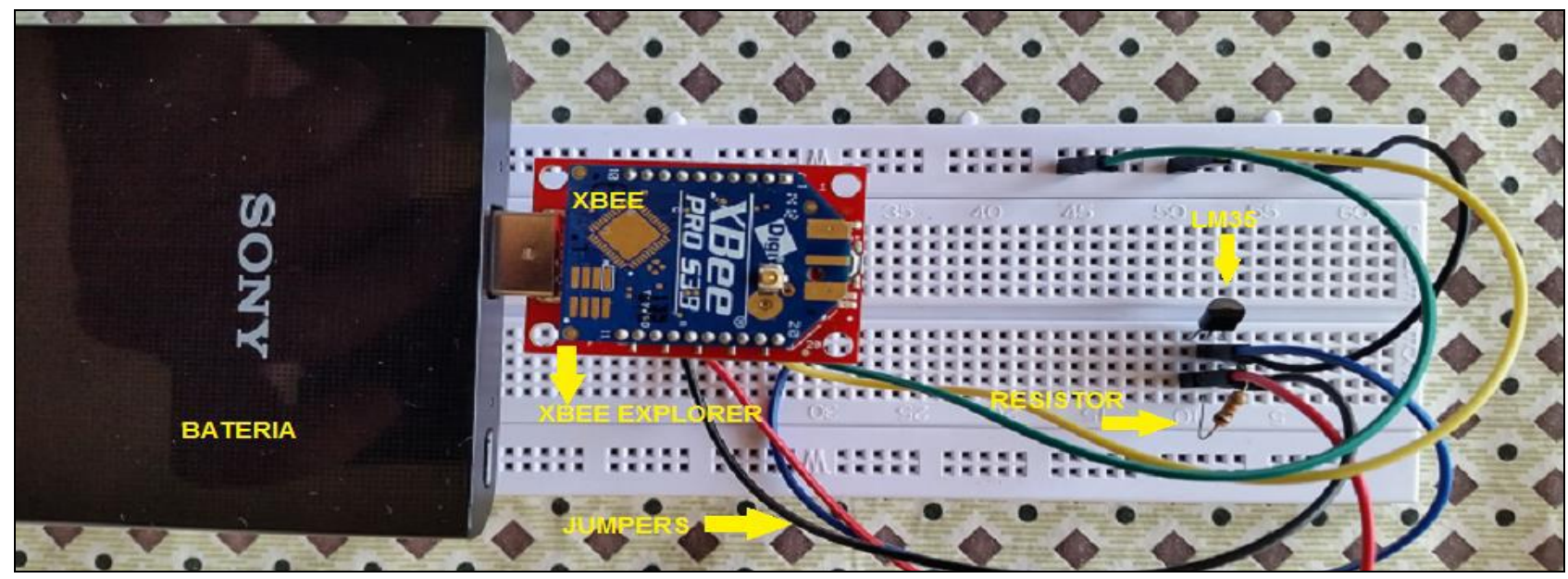

Figura 8: Protótipo de aquisição dos sinais de campo (Fonte: Goulart, 2015).

\section{5 - Teste de alcance}

\subsection{1 - Área urbana}

O primeiro teste de alcance dos módulos foi feito em área urbana. Um módulo XBee 1 fícou instalado no laboratório de eletrônica do CEFET-MG Campus Araxá, a uma altura aproximada de 
1,70 metros. O segundo dispositivo XBee 2 foi instalado a uma altura de 1,50 metros, em um carro. O carro andou ao redor do dispositivo XBee 1 até achar o ponto mais distante entre os módulos em que a comunicação se mantinha estável. A Figura 9 mostra a maior distância alcançada: aproximadamente 342 metros.

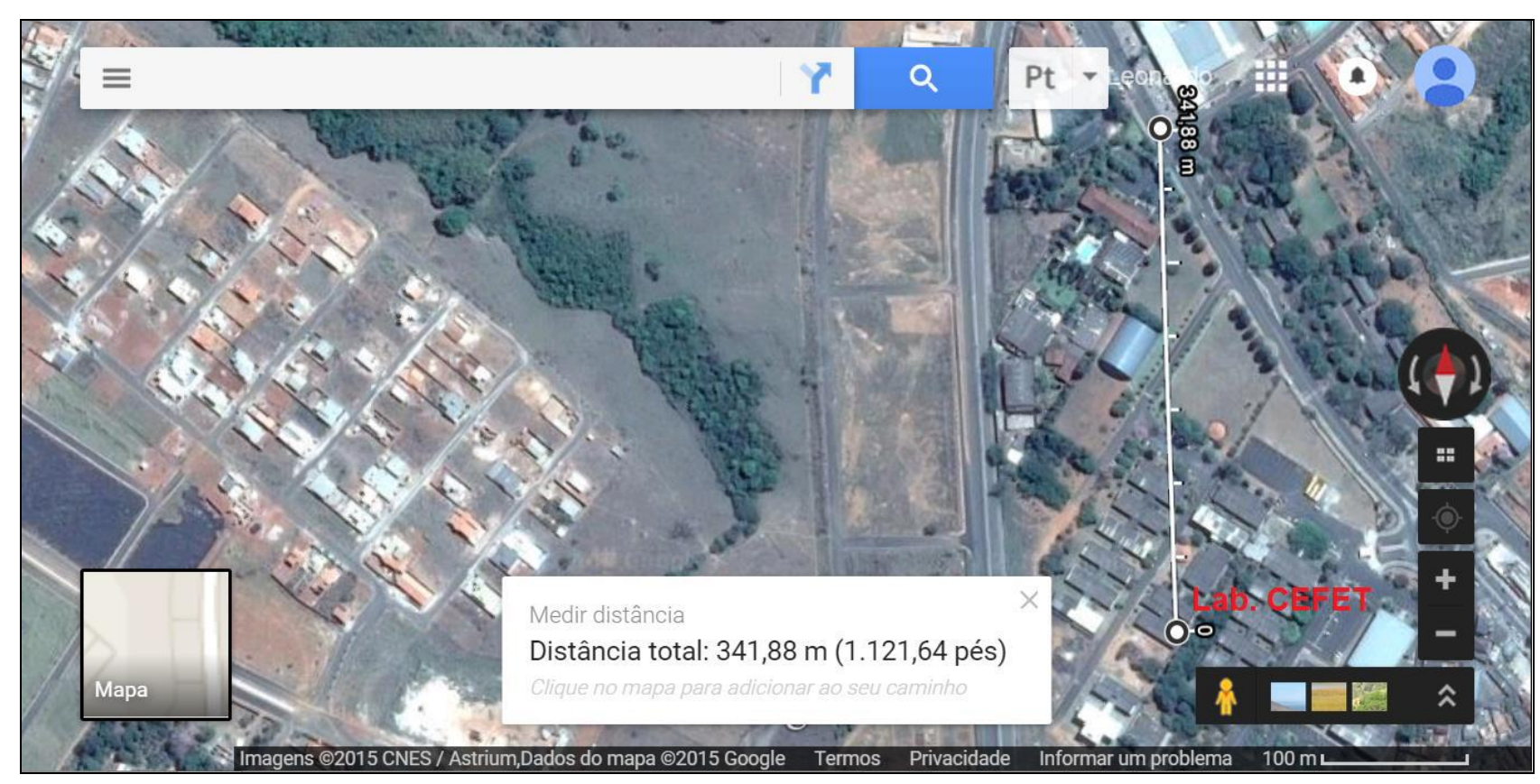

Figura 9: Teste de alcance em área urbana (Fonte: Goulart, 2015).

\subsection{2 - Área de mina}

O teste de alcance na área da mina foi também o teste de todo sistema de monitoramento. Realizado na mina F4 (Vale Fertilizantes Complexo Mineroquímico de Araxá), em um dos poços lá instalados (PP-06, corresponde à nomenclatura interna de controle dos poços), foi colocado o sistema de aquisição de dados de campo (Figuras 10 e 11). 


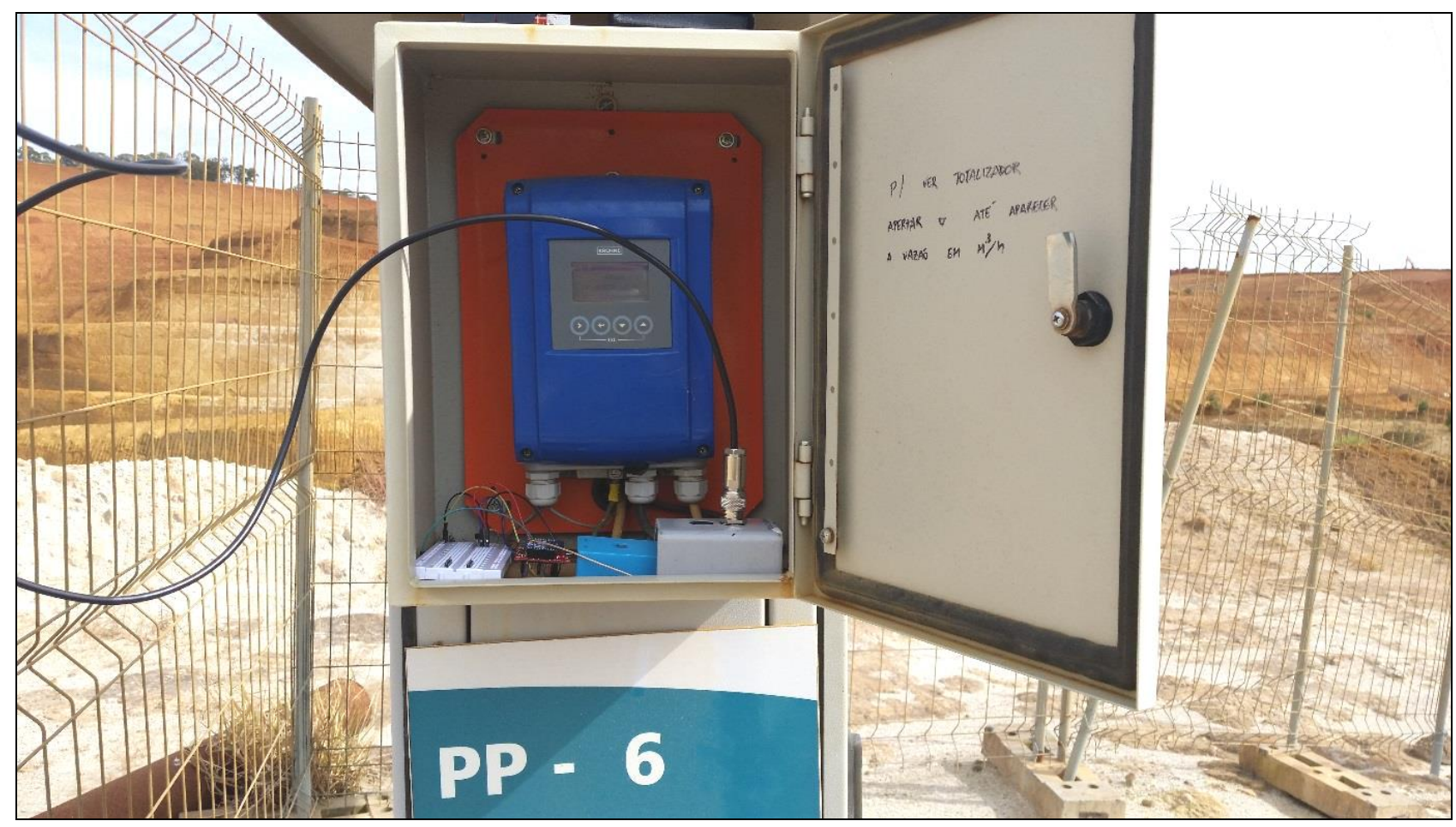

Figura 10: Sistema de aquisição de dados instalado em uma mina(Fonte: Goulart, 2015).

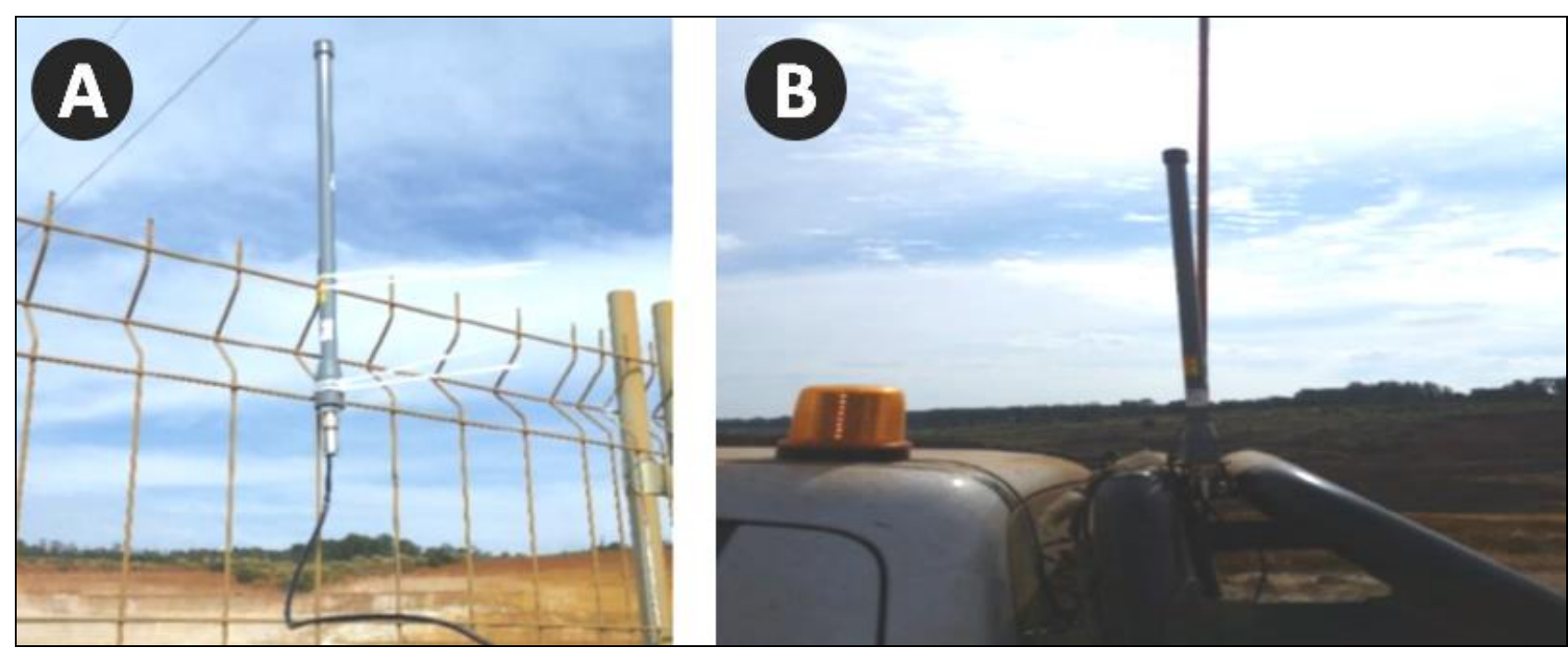

Figura 11: A) Instalação da antena no poço. B) Instalação da antena do XBee coordenador. (Fonte: Goulart, 2015).

Após a instalação do dispositivo PP-01 no poço, instalou-se a antena do dispositivo PP-02 em um suporte externo de uma caminhonete (Figura 11B).

Assim, dentro da caminhonete ficaram o PP-02, que foi apenas energizado, e o sistema de interface e aquisição (coordenador) (Figura 12).

O local mais adequado para o monitoramento dos poços tubulares profundos é o mirante da mina, uma vez que é um local seguro, acessível, de pouco movimento de veículos, e com visão privilegiada da mina. Após instalação do XBee PP-01, o veículo saiu do local em direção ao mirante. Em movimento, foi possível observar que a comunicação entre os dispositivos se mantinha 
ou cessava. Na maior parte do trajeto, a comunicação se estabeleceu de forma normal. Apenas em alguns pontos de obstrução total houve perda de comunicação.

No mirante da Mina (Figuras 13 e 14), o monitoramento foi possível e manteve-se estável.

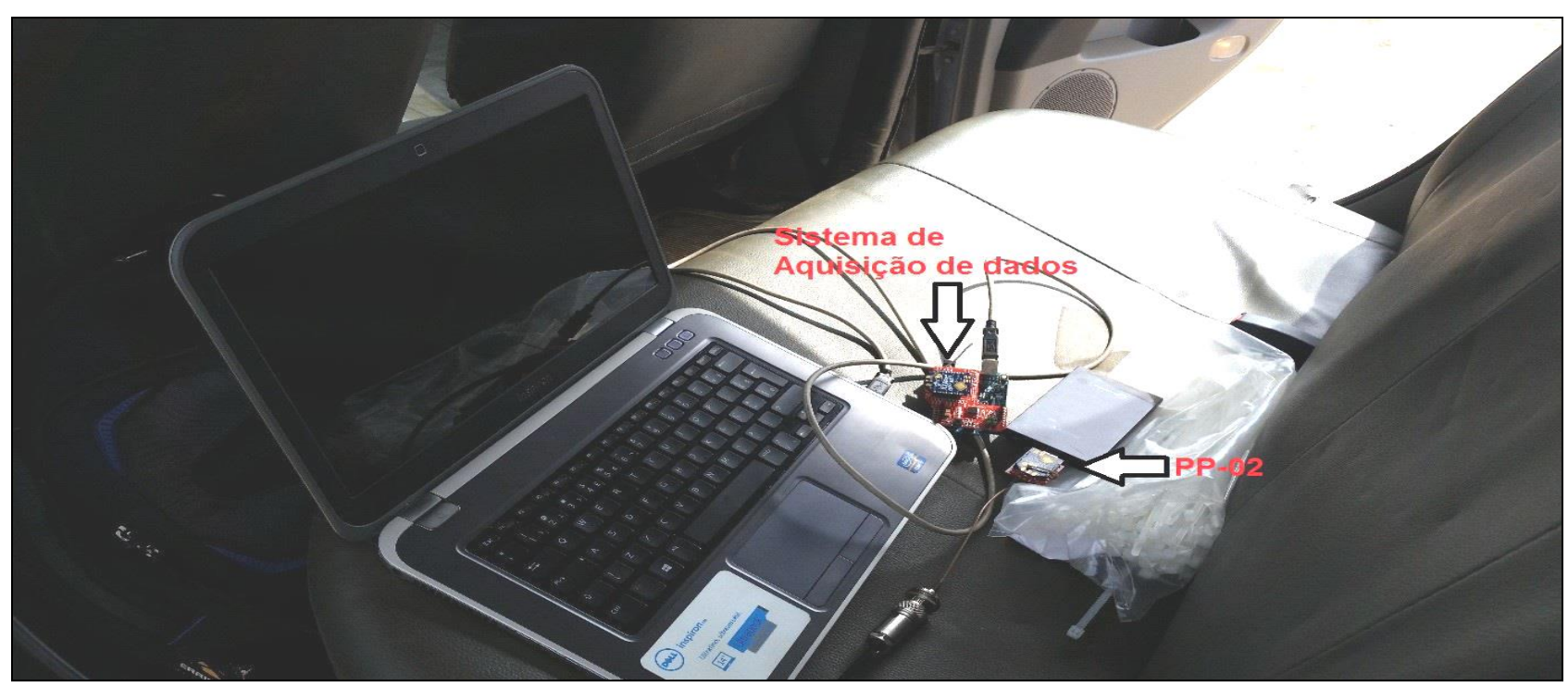

Figura 12: Sistema de aquisição de dados e PP-02 dentro da caminhonete (Fonte: Goulart, 2015).

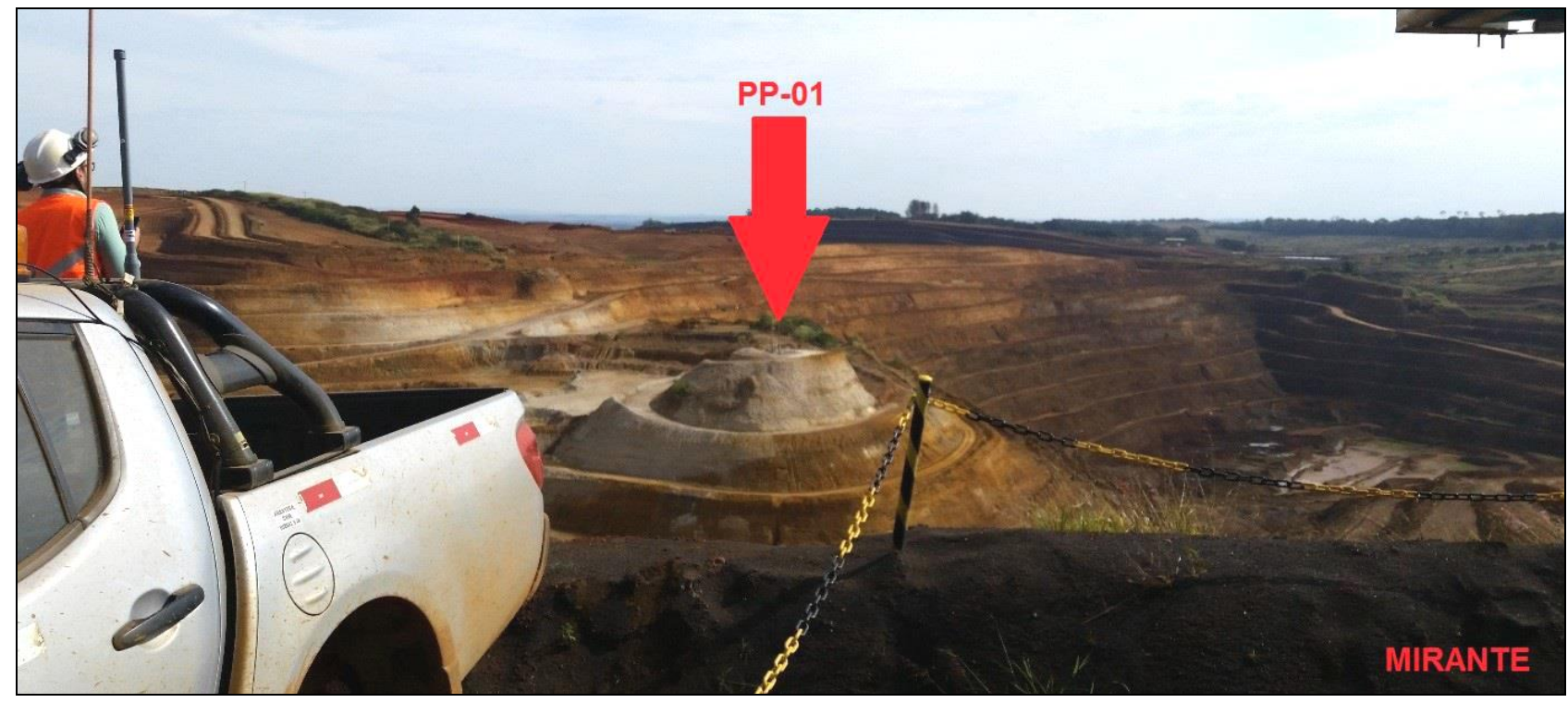

Figura 13: Mirante da mina F4 (teste do sistema de monitoramento) (Fonte: Goulart, 2015). 


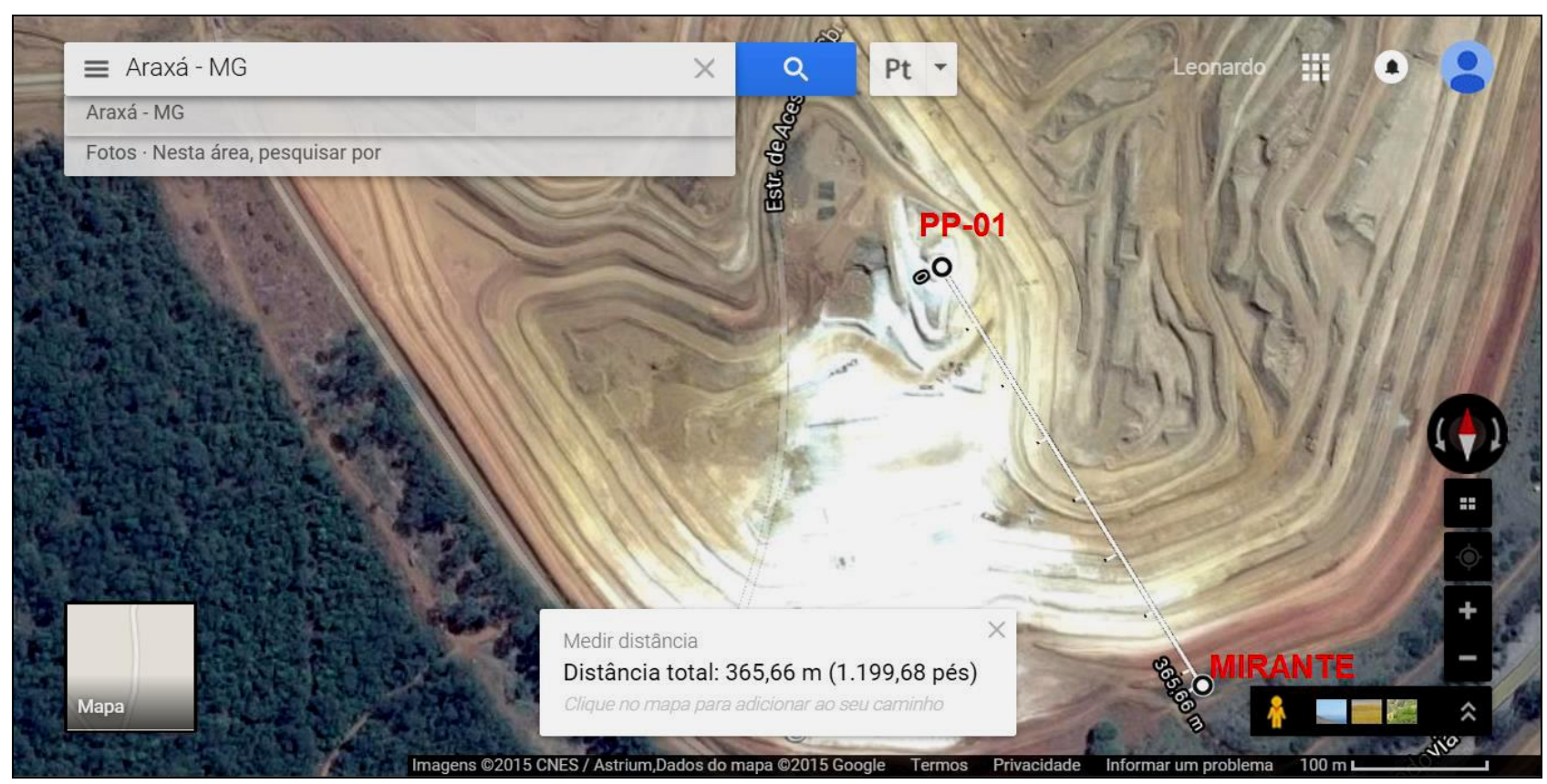

Figura 14: Distância entre dispositivos mirante e PP-01. (Fonte: Goulart, 2015).

Por último, foi feito mais um teste, dessa vez na cota mais baixa da mina. Assim como no mirante, obteve-se sucesso na monitoração do PP-01 (Figuras 15 e 16).

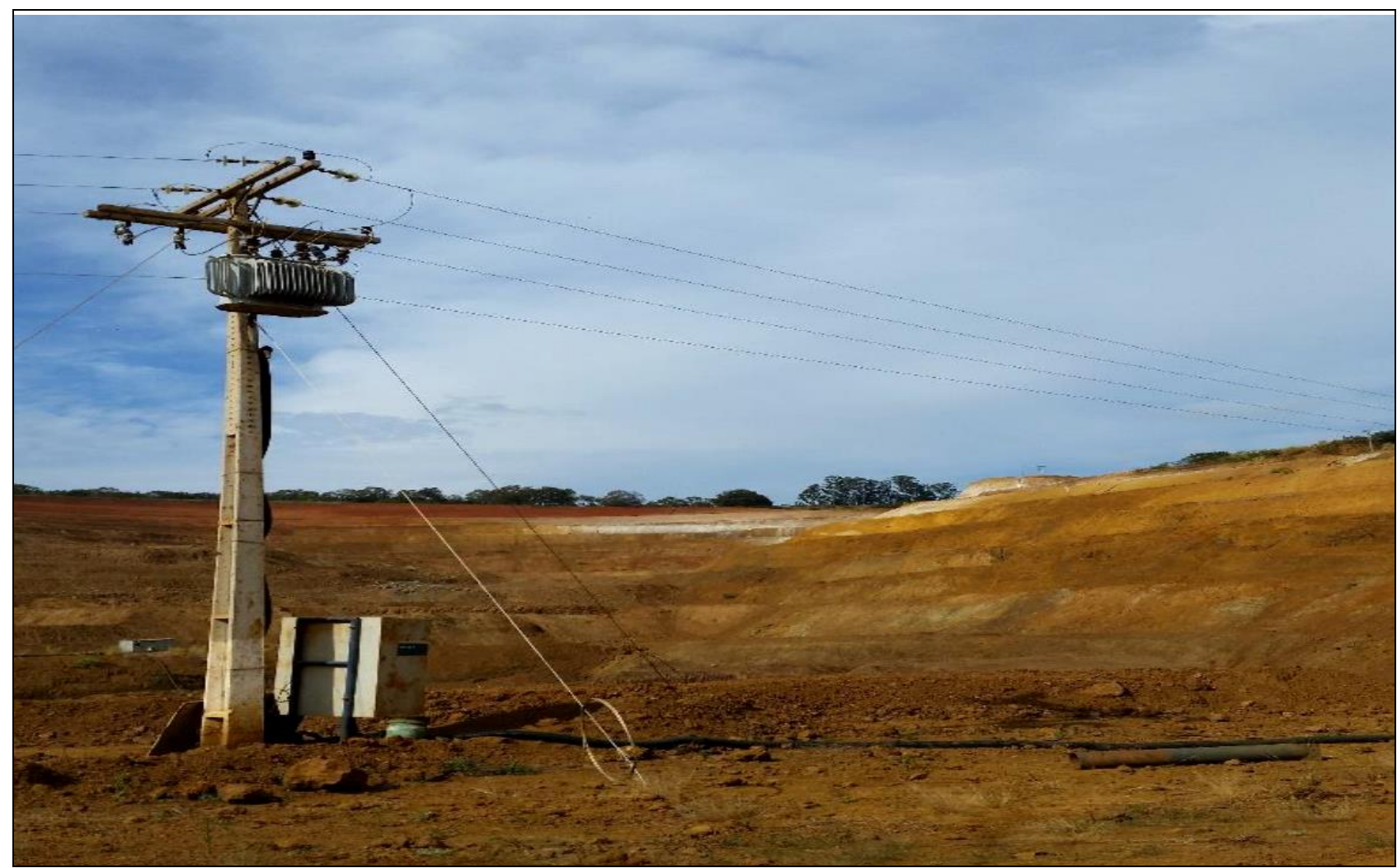

Figura 15: Poço instalado na cota mais baixa da mina. (Fonte: Goulart, 2015). 


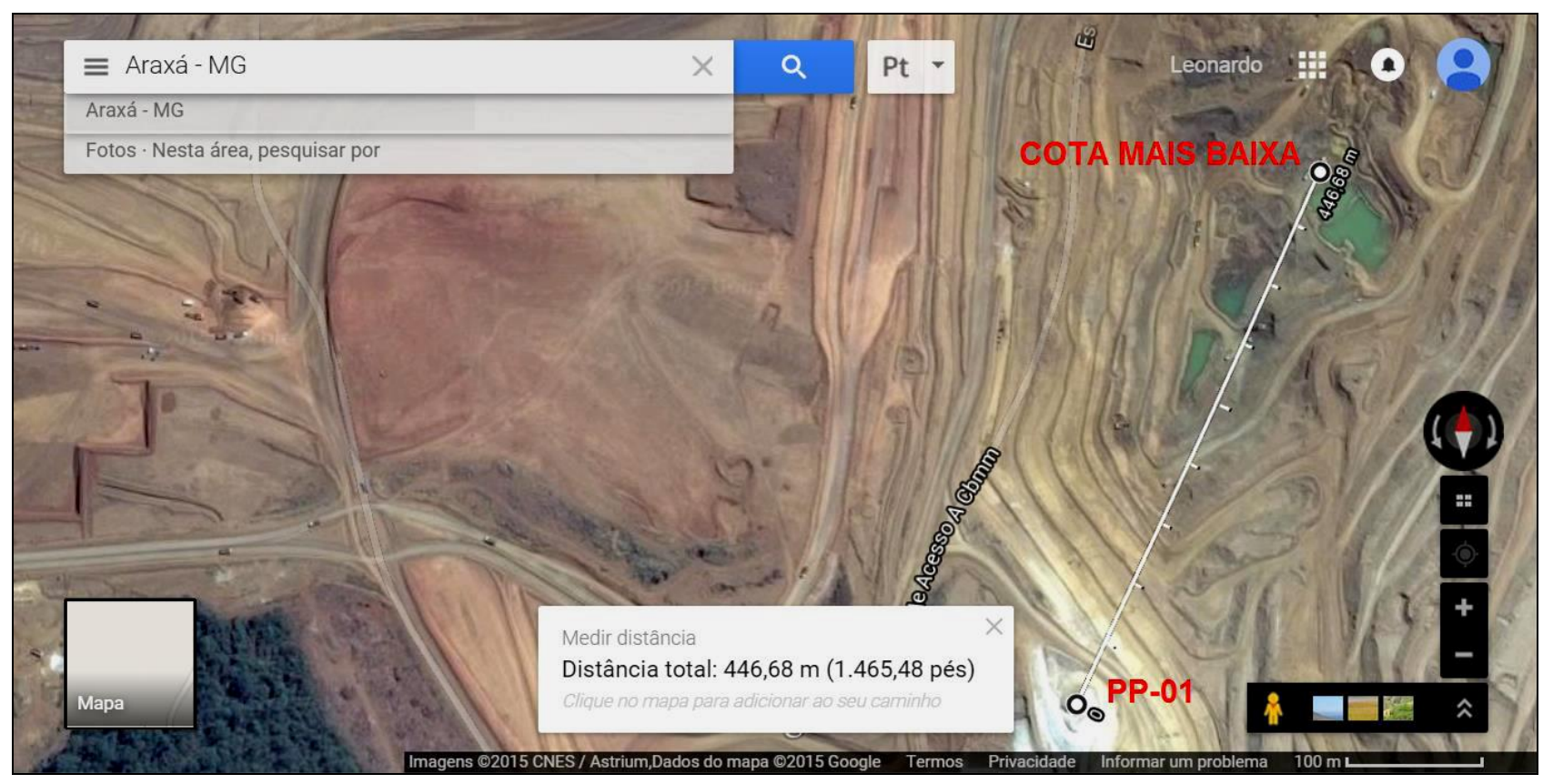

Figura 16: Distância entre o PP-01 e a cota mais baixa da mina. (Fonte: Goulart, 2015).

\section{6 - Análise dos resultados}

Em relação ao sistema de transmissão de dados, pode-se observar que os módulos de radiotransmissão escolhidos são um dos mais modernos, com muitas aplicações diferentes e possuem um novo protocolo proprietário com vantagens em relação ao ZigBee.

O modo de transmissão transparente possui configuração simples e não necessita de tratamento de dados para saber o que acontece com o outro dispositivo. Esse modo não foi aplicado no trabalho porque não é possível inserir nele mais dispositivos.

O modo de transmissão API é o coração do projeto, uma vez que essa configuração permite a inserção de vários dispositivos numa mesma rede e adota frames de dados, que definem operações e eventos para cada dispositivo.

A comunicação dos XBee's com o software Microsoft Visual Studio só foi possível com a criação do sistema de interface e aquisição de dados.

O aplicativo de supervisão dos poços possui uma interface gráfica intuitiva com as principais informações do poço e identificação de falha de comunicação dos dispositivos instalados.

O teste de alcance em área urbana mostrou o poder do dispositivo em relação à coexistência, isto é, a capacidade dos dispositivos sem fios de diferentes tecnologias poderem operar perto um dos outros, sem interferência, na mesma faixa de frequência e os obstáculos que estavam à frente dos dois dispositivos.

O teste de alcance na mina foi realizado com sucesso e abrangeu todo o sistema de monitoramento. Ele revelou que é possível utilizar essa tecnologia para monitorar poços tubulares 
na área. Isso só foi possível com a instalação do sistema de aquisição de sinais no PP-01, que enviou, de forma periódica, os prováveis sinais que os equipamentos de campo podem gerar. Nos dois testes dentro da mina, a maior distância alcançada foi de aproximadamente 447 metros.

\section{5 - CONCLUSÃO}

Apesar de existir no mercado diversos sistemas de telemetria em operação, este projeto alcançou o seu objetivo geral ao criar um protótipo de baixo custo, controle simultâneo e confiável dos poços tubulares, contornando, assim, os problemas que a coleta manual possa apresentar.

A partir de um dispositivo radiotransmissor XBee - conectado à uma estação remota (notebook) montada dentro de uma caminhonete parada no mirante da mina - conseguiu-se receber as informações de funcionamento, vazão e totalização de água de um poço localizado a uma distância aproximada de 366 metros um do outro, podendo ser superior a 450m caso não haja obstáculos físicos que prejudiquem a visada entre o poço e o receptor (notebook, celular, tablet, etc).

O projeto foi dividido em quatro sistemas para facilitar seu o desenvolvimento. No primeiro (rádio transmissão), configurou-se os módulos. No segundo (interface e aquisição de dados), programou-se um Arduino, que proporcionou a integração entre os radiotransmissores por meio do aplicativo de supervisão e de tratamento de dados, desenvolvido no terceiro sistema. No quarto, simulou-se os sinais físicos advindos dos instrumentos instalados em um poço. Os testes de alcance realizados na mina determinaram a eficiência do protótipo.

Este mesmo protótipo pode ser instalado em poços de abastecimento e/ou monitoramento localizado em áreas urbanas, fazendas, chácaras, condomínios, etc., reduzindo o custo das medições de vazão, volumes explotados, níveis estáticos e dinâmicos, etc., além de minimizar ou até mesmo evitar possíveis erros de leitura, e tornar o monitoramento dos poços algo acessível a toda população. O baixo custo de implantação deste sistema poderia tornar a legalização dos poços clandestinos algo viável e agradável aos usuários ilegais. 


\section{6 - REFERÊNCIAS BIBLIOGRÁFICAS}

ABUD, M. C. et al. Operação e manutenção dos poços de rebaixamento em mina a céu aberto, um estudo de caso do complexo mineroquímico de Araxá da Vale Fertilizantes. In: CONGRESSO BRASILEIRO DE ÁGUAS SUBTERRÂNEAS, 18, ENCONTRO NACIONAL DE PERFURADORES DE POÇOS, 19., FENÁGUA - FEIRA NACIONAL DA ÁGUA, 8., 2014, Belo Horizonte. Anais... Belo Horizonte: Associação Brasileira de Águas Subterrâneas, 2014.

$\begin{array}{llll}\text { ALBACORE. } & \text { XBee-PRO } & \text { 900HP. } & \text { Disponível em }\end{array}$ <http://www.albacore.com.br/index.php/produtoss/solucoes-embarcaveis/modulos-zigbee-erf/modulos-rf-ponto-para-multiponto/xbee-pro-900hp>. Acesso em 7 jun. 2015.

ALLBIZ. Unidades comerciais de contabilidade de gás natural, eletricidade, calor e água. Disponível em <http://www.br.all.biz/unidades-comerciais-de-contabilidade-de-gs-natural-bgr1437>. Acesso em 26 jul. 2015.

BALLOCK, I. R. Protótipo de um sistema para supervisão de equipamentos industriais. 2003. 59f. Dissertação (Graduação em Ciências da Computação) - Universidade Regional de Blumenau, Blumenau, SC, 2003. Disponível em <http://www.inf.furb.br/ pericas/orientacoes/CLP2003.pdf〉. Acesso em 20 jul. 2015.

BERTACHINI, A. C.; ALMEIDA, D. C. O rebaixamento do nível d'água em mineração e obras civis. In: ENCONTRO NACIONAL DE PERFURADORES DE POÇOS, SIMPÓSIO DE HIDROGEOLOGIA DO SUDESTE, 13., 2003, Petrópolis, RJ. Anais. Petrópolis: Associação Brasileira de Águas Subterrâneas, 2003.

BONIFÁCIO, T. G. Implementação de um protocolo mesh multi-hop baseado e algoritmo de roteamento geográfico para redes de sensores sem-fio. 2010. 141f. Dissertação (Mestrado em Engenharia Elétrica) - Universidade de São Paulo, São Carlos, SP, 2010.

CORTELETTI, D. Introdução à programação de microcontroladores Microchip PIC. Serviço Nacional de Aprendizagem-RS/Centro Tecnológico de Mecatrônica, 2006. 
FAGUNDES, F. D. Simulação de controle de processo industrial utilizando protocolo de comunicação ZigBee. 2013. 63f. Dissertação (Graduação em Engenharia de Automação Industrial) Centro Federal de Educação Tecnológica de Minas Gerais, Araxá, MG, 2013.

GOUlaRT, L. A. R. Monitoramento Remoto de Poços Tubulares Profundos na Mineração. 2015. 84f. Dissertação (Graduação em Engenharia de Automação Industrial) - Centro Federal de Educação Tecnológica de Minas Gerais, Araxá, MG, 2015.

LUGLI, A. B.; SOBRINHO, D. G. Tecnologias wireless para automação industrial: WIRELESS_HART, BLUETOOTH, WISA, WI-FI, ZIGBEE E SP-100. In: CONGRESSO INTERNACIONAL E EXPOSIÇÃO DE AUTOMAÇÃO, SISTEMAS E INSTRUMENTAÇÃO, 16., 2012, São Paulo. Anais... São Paulo: Associação Sul-Americana de Automação/ Brazil Automation, 2012.

SILVA, M.V.A., Castro, S.A.B, Trindade, A.C.C., Abud, M.C., Saito, M.K., Filho, F.S. 2012. Proposta de geração de mapas potenciométricos 2D e 3D da mina F4 da Vale Fertillizantes S.A., Araxá MG. XVII Congresso Brasileiro de Águas Subterrâneas, Bonito MS.

TRINDADE, D. F.; TRINDADE, L. S. P. As telecomunicações no Brasil: do Segundo Império até o Regime Militar. São Paulo: Centro Federal de Educação Tecnológica de São Paulo, 2004.

VIEIRA, M. A. Sistema de telemetria para robôs móveis. 2011. 91f. Dissertação (Graduação em Engenharia da Computação) - Universidade Federal do Vale do São Francisco - Campus de Juazeiro, Juazeiro, BA, 2011.

ZEINDIN, D. C. A. et al. A Tecnologia do futuro Wi-Fi (Wireless Fidelity). Blumenau, SC: Universidade Regional de Blumenau, 1999. 